\title{
ANÁLISE DO DISCURSO DA SECRETÁRIA DE EDUCAÇÃO DO ESTADO DE GOIÁS.
}

\author{
Soraia Rodrigues Chaves. Universidade Federal de Goiás/Regional Jataí - Professora \\ do Curso de Pedagogia/UAE-EDU - rodrigues.soraia@hotmail.com
}

RESUMO. A Análise proposta para este trabalho, refere-se ao modelo tridimensional de discurso: a análise da prática discursiva, do texto e da prática social. Uma flexão baseada nos pressupostos da análise do discurso, acerca dos discursos da Secretária de Educação de Goiás Professora Doutora Raquel Alexandre Teixeira e os temas que compõem suas falas em entrevistas relacionadas a questões sociais e políticas onde a questão central é a Educação Pública. A análise do discurso no estudo da linguística crítica e a análise da linguagem na percepção das mudanças sociais e na ideologia poderá nos fazer compreender os motivos pelos quais sua defesa pela qualidade da escola pública apresente algumas contradições, conflitos ideológicos, pressupostos neoliberais e pode se contrapor a um outro conceito de qualidade necessária para se construir uma outra sociedade mais consciente e crítica. O nosso corpus de trabalho está composto pelas falas da Professora Raquel Teixeira em entrevistas recentes na mídia regional sobre educação e gestão da escola pública, o nosso objeto de análise é o seu discurso político. A análise do discurso é o nosso fundamento metodológico. De linha francesa tendo como bases principais o Discurso e Mudança Social de Norman Fairclouch, também em Stephen J. Ball, cuja base reflete a Performatividade, Privatização e o Pós Estado do Bem Estar-Social), também alinhava a base temática A Reforma do Estado dos anos 90 e Mecanismos de Controle, de Luiz Carlos Bresser Pereira. Nossa pretensão nesse artigo é levantarmos alguns pontos de reflexão no discurso político, que nos possibilite contribuir com o debate das mudanças sociais, encontrando na prática social da Secretária de Educação de Goiás Professora Raquel Teixeira a lógica racional que norteia seu discurso. Nesse sentido, esperamos que novos elementos possam ser evidenciados à luz da análise do discurso e mudança social de Fairclouch e com o método da linguística crítica des-cobrir identidade do sujeito, as relações sociais e os sistemas de conhecimento e poder.

Palavras chave: Análise do Discurso. Discurso Político. Educação.

\section{ANALYSIS SPEECH GOIÁS STATE EDUCATION SECRETARY.}

ABSTRACT. The analysis proposed for this article, refers to the three-dimensional model of discourse: the analysis of the discursive practice, text and social practice. A bending based on assumptions of discourse analysis, about the speeches of the Secretary of Goiás Professor Raquel Alexandre Teixeira Education and the themes that make up their lines in interviews related to 
Volume,13, n. 1: ano 2017

social and political issues where the central issue is the Public Education. The discourse analysis in Linguistics critical study and analysis of language in perception of social change and ideology can make us understand the reasons for his defense for public school quality presents some contradictions, ideological conflicts, neoliberal assumptions and can counter to another concept of quality necessary to build another more conscious and critical society. Our work corpus is composed of lines of Raquel Teixeira Professor in recent interviews in the regional media on education and management of public schools, our object of analysis is its political speech, you. The discourse analysis is our methodological foundation. The French line with the main bases Discourse and Social Change Norman Fairclouch also in Stephen J. Ball, whose base reflects the (Performativity, Privatization and Post State Well being-Social), also aligned the thematic basis Reform State 90s and Control Mechanisms, Luiz Carlos Bresser Pereira .Our intention in this article is we raise some points of reflection in political discourse, which enables us to contribute to the discussion of social, meeting the social practice of the Secretary of Education Goias Professor Raquel Teixeira rational logic that guides his speech. In this sense, we hope that new elements can be evidenced in the light of discourse analysis and Social Fairclouch Change and the linguistic critical method (Fowler et al, 1979; Kress and Hodge) dis-cover the subject's identity, social relations and the knowledge and power systems.

Key-words. Discourse Analysis. Political speech. Education. Management.

\section{INTRODUÇÃO}

O nosso corpus de trabalho compõe se de algumas falas da professora Raquel Teixeira em entrevistas sobre Educação e o nosso objeto de análise é seu discurso Político em relação a Escola Pública, Estado e Educação.

Sustentamos esta análise em fundamentos da análise do discurso - AD, de linha francesa, embasando-nos principalmente no Discurso e Mudança Social de Norman Fairclough, também em Stephen J. Ball em Perfomatividade, Privatização e o Pós Estado do Bem-Estar-Social e ainda em A Reforma do Estado Dos Anos 90 e Mecanismos de Controle de Luiz Carlos Bresser Pereira, para que se possa situar o lugar de onde se fala e o contexto que compõe esse discurso. O que se pretende neste estudo é refletir sobre o discurso político educacional da Secretária de Educação de Goiás Professora Raquel Teixeira e através do mesmo demonstrar as contradições, ideologias neoliberais e a eminente defesa da meritocracia, para assim contribuir com o debate das mudanças sociais, explicitando elementos que possam trazer à luz, através da análise do discurso e mudança social de Fairclough e com o método da linguística crítica, des- cobrir a identidade do sujeito, as relações sociais e os sistemas de conhecimento e poder. 
Volume,13, n. 1: ano 2017

Estruturamos este texto em três partes: a primeira refere-se a história de Raquel Teixeira, a segunda a uma breve abordagem de alguns conceitos da AD (análise do discurso) e finalmente a terceira, pauta-se na transcrição do discurso político educacional da Professora Raquel Teixeira realizado através das entrevistas recentes concedidas nas mídias em geral disponíveis no (You Tube), transformando sua oralidade em texto para que seja possível a análise do seu discurso, principalmente no seu conteúdo e forma.

\subsection{Um pouco da história de Raquel Teixeira.}

Formada em Letras, mestre pela UnB (Universidade de Brasília) e doutora em Linguística pela Universidade da Califórnia, EUA (Estados Unidos da América). É professora universitária titular da UFG (Universidade Federal de Goiás). Ocupou o cargo de Secretária de Educação de Goiás em dois mandatos do governo de Marconi Perillo do PSDB (Partido da Social Democracia Brasileira) nos períodos de 1999 a 2001 e 2005 a 2009. Retornando em 2015 para mais um mandato do citado governador. Foi eleita deputada federal por Goiás também pelo PSDB (Partido da Social Democracia Brasileira) por dois mandatos.

Surgia então no fim dos anos 80 o PSDB (Partido da Social Democracia Brasileira), com a perspectiva de organizar uma alternativa social democrata em meio ao conjunto de forças políticas que emergia no país. Concebendo como princípios do programa partidário algumas indicações do Consenso de Washington principalmente no que se refere a privatizações de empresas estatais.

Suas alianças estratégicas com o DEM (Partido dos Democratas) antigo PFL (Partido da Frente Liberal) e que antes foi PDS (Partido Democrático Social) E ARENA (Aliança Renovadora Nacional), forças extremamente conservadoras, o levou para a direita. Quando assume o poder em 1994, adota uma política econômica com abertura comercial sem contrapartida, privatização de empresas (em processos questionados) redução do papel do Estado (desarticulando e minando órgãos) e ênfase sobre a regulação, enfraquecendo políticas estratégicas do governo. Porém quando propôs a emenda constitucional no capítulo econômico da Constituição Brasileira, extinguindo qualquer viés nacionalista se mostrou um partido com forte expressão neoliberal. 
Volume,13, n. 1: ano 2017

Portanto, a mudança no papel dos Estados social -democratas faz parte de uma transformação mais ampla na arquitetura política. É a mudança na responsabilidade do Estado para a realização para a responsabilidade com a mensuração e a auditoria abre a possibilidade de duas outras mudanças políticas. Primeiro, uma vez livre da responsabilidade exclusiva da prestação direta de serviço, o Estado pode considerar vários prestadores potenciais de serviços-públicos, voluntários e privados. Segundo, isso também permite considerar modelos alternativos de financiamentos e a participação de financiadores privados para desenvolver a infra-estrutura do setor público. (BALL,2004 p.1105- 1126)

Desta forma conhecendo o lugar de onde a Secretária de Educação de Goiás Professora Raquel Teixeira realiza seu discurso educacional e político, podemos compreender melhor a análise de discurso de Michel Foucault e sua preocupação com a ética: "Como o indivíduo deve constituir-se ele próprio como um sujeito moral de suas próprias ações". (FAIRCLOUGH,1984;352)

\subsection{Alguns dos conceitos da análise do discurso}

A análise de discurso também conhecida como AD (análise do discurso) é uma disciplina com origem francesa que surgiu na década de 1960 com Michel Pêcheux. Seu objeto de estudo é o Discurso e constitui -se de três áreas do conhecimento: a Linguística, a Psicanálise e o Marxismo Histórico.

Esse recorte se faz com a obra de Norman Fairclough traduzida no Brasil pela UnB (Universidade de Brasília) e do Grupo de pesquisa de linguagem e ideologia. A obra de Fairclough Discurso e Mudança Social abre caminho para uma análise linguística capaz de também analisar e investigar na linguagem questões sociais, culturais e políticas.

Para desenvolver a análise do discurso vamos considerar a estruturação do texto, assim como os processos articulatórios da construção desse texto, porém levando em consideração também o contex to histórico e político onde está situado, realizando uma análise crítica do discurso que busca des-cobrir "as funções ideológicas do Estado" (ALTHUSSER,1985, p.09-10).

Analisando o discurso é possível refletir sobre o poder da linguagem e das palavras distribuídas em sua arqueologia não aleatoriamente, mas formando um contexto significativo capaz de demonstrar a luta pelo poder e as intenções políticas de convencimento. 
Volume,13, n. 1: ano 2017

\section{O Discurso de a Análise do Discurso.}

Trataremos nesta parte da análise do discurso político e educacional da Professora Raquel Teixeira Secretária de Educação do Estado de Goiás no instante em que o Estado anuncia a transferência das escolas públicas estaduais para as 0S (organizações sociais) que a partir de agora passarão a administrar estas instituições. Esta entrevista foi concedida para vários seguimentos da mídia e tem como objetivo trazer esclarecimentos sobre estas terceirizações, foi transcrita aqui para transformar o texto oral em texto escrito tornando possível sua análise.

Descreveremos a entrevista que a partir de agora chamaremos discurso ao mesmo tempo em que praticamos a análise linguística e social. Para isso vamos desenvolvendo algumas explanações acerca das medidas implantadas pelo Estado na execução de mudanças na administração das escolas públicas.

Começaremos por dar significado ao processo de terceirização, que no interior do discurso é chamado de gestão Compartilhada localizando este fenômeno dentro das reformas do Estado.

\subsection{O discurso}

A reforma do estado envolve quatro problemas que, embora interdependentes, podem ser distinguidos: (a) um problema econômico - político - a delimitação do tamanho do Estado: (b) um outro também econômico político, mas que merece tratamento especial - a redefinição do papel regulador do Estado; (c) um econômico - administrativo - a recuperação da governança ou capacidade financeira e administrativa da implementar decisões políticas tomadas pelo governo; e (d) um político - aumento ou capacidade política do governo de intermediar interesses, garantir legitimidade, e governar. Na delimitação do tamanho do Estado estão envolvidas as ideias de privatização, "publiticização" e terceirização. (BRESSER, 1998 p.49-50)

Neste momento, apresentamos o discurso da Secretária Raquel Teixeira:

$\neg$ Para os estudantes a situação vai melhorar. Eles terão uma escola que terá um apoio para parte administrativa financeira e, terão um diretor voltado para parte pedagógica, terão professores valorizados e estimulados trabalhando no seu conhecimento. Eu acho até que as escolas com OS (Organizações Sociais) vai virar objeto de consumo da maioria dos estudantes.

$\neg$ A gente vai ter uma escola cada vez melhor, com laboratórios, com apoio. Não vai acontecer no primeiro momento, mas a tendência nos próximos anos é que esta Gestão Compartilhada, traga benefícios para o estudante em 
Volume,13, n. 1: ano 2017

todos os aspectos: da aprendizagem, dos equipamentos existentes, da convivência, do avanço.

$\neg$ O que a gente quer. Essa é a minha convicção pessoal e que eu me pauto por ela sempre Escola de qualidade é aquela em que o aluno aprende a superar os desafios da escola e da vida. O aluno vai ter mais elementos para aprender, a para se equipar, para superar os desafios da escola.

$\neg$ que eu quero é que os nossos estudantes sejam profissionais de sucesso, que façam uma universidade, que tenham um bom emprego,_que construam famílias e empregos estáveis, que tenham uma vida feliz. O que a gente quer é que o aluno seja feliz, que as pessoas sejam felizes. Só que o mundo hoje é complexo. Ele é exigente. Ele é competitivo e pra ser feliz você precisa de algumas condições: a mais importante delas é o repertório intelectual de conhecimentos da parte de cognição de habilidades sócio emocionais que você precisa para se dar bem na vida. Os estudantes serão muito beneficiados.

\subsection{A análise do discurso}

Este discurso apresenta uma forte intertextualidade na medida em que apresenta diferentes campos e presenças. (Fairclough). A presença do Estado executando suas reforma de forma firme e consistente e a presença de Raquel Teixeira minimizando as imposições e produzindo um discurso de defesa e de convencimento dos interesses do Estado, usando para tanto a autoridade de quem teve uma trajetória construída na escola pública. Num outro momento quando se apresenta a Secretária de Educação Do Estado para processar o discurso oficial do Estado promovendo o convencimento dos benéficos da transferência das escolas públicas para as OS (Organizações Sociais) apresentando as estruturas de investimento Estatal.

As palavras vão formar grupos de palavras e significados (Williams, 1976: 19,) que poderão dizer muito dentro do contexto social e político por isso nosso foco será no significado e não na lexicalização dos significados. No significado Potencial, aquele que é comum a todos.

A palavra gente repetida várias vezes no texto pode ser uma representação das entidades envolvidas no processo: Raquel Teixeira, estudantes, sociedade, ou ainda uma demonstração da relação binária Estado/instituições privadas ou associadas ao grupo de palavras poderá representar uma intertextualidade hegemônica de Nós (quem domina) pra Vocês (dominados). Isso demonstra como o significado potencial pode ser ideológica e politicamente investido na constituição discursiva de um conceito cultural chave. 
Volume,13, n. 1: ano 2017

$\neg$ Eles terão uma escola que terá um apoio administrativo e financeiro. Definindo e ou delimitando aqui o papel do Estado. Apresentando um programa de publicização em curso.(Bresser Pereira. 1998.). Uma proposta Neo conservadora de reduzir o papel do Estado criando um espaço privado dentro do espaço público sob a lógica de que com a desoneração dessa regulação o Estado se tornará mais ágil.

Consumo, também em destaque - objeto de consumo - reporta a uma sociedade do consumo, uma mercantilização, nesta perspectiva a educação se transforma em mercadoria onde estudantes serão os consumidores. $\mathrm{O}$ que pode representar como Stephen J. Ball descreve: Tudo isso mostra a história da mudança de face do capital enquanto está readequando as instituições e as pessoas para o lucro (Ball apud ARTHUR ANDERSEN.2004, p.1112).

Anunciando já um projeto de escolha da escola como um produto que se consome de acordo com sua condição econômica ou seja quem pode mais escolhe uma escola para ricos quem pode menos escolhe uma escola para pobres (Ball). Apresentado uma falsa ideia de que se escolhe qualidade comprando educação. Um claro projeto neoliberal com uma lógica privatista.

O significado de qualidade ou no grupo de palavras escola de qualidade também pode ser entendido como excelência na prestação de serviços que no mercado empresarial desencadeia a competitividade e a concorrência para colocar nesse mercado um profissional de sucesso, com famílias e empregos estáveis. Nesta conjuntura as habilidades, culturas e éticas desenvolvidas para enfrentar os desafios dessa escola e dessa vida possam ser principalmente de consumo e incentivo ao lucro baseado também na produtividade. Pensar na educação como forma de produção o que é contraditório com o objetivo de construção de uma sociedade mais justa e igualitária no sentido de que os conceitos de igualdade e competitividade se contrapõem.

$\mathrm{O}$ ato de ensinar e a subjetividade do professor ambos sofrem profundas mudanças como o novo panopticismo da gestão (qualidade e de excelência) e das novas formas de controle empresarial(por meio de marketing e da concorrência).(BALL,2004,p.1118)

Organização social e gestão compartilhada. Buscamos em Stephen J. Ball um significado para esta relação e esse grupo de palavras de acordo com a prática social 
Volume,13, n. 1: ano 2017

apresentada no discurso: "A gestão é uma ciência promíscua”. Na subjetividade do discurso está também se discutindo a relação da parceria, uma vez que se enaltece de forma intensa a superioridade da gestão compartilhada em relação ao Estado criando uma uma imagem futurista e idealizada de uma escola equipada, com professores valorizados e motivados coisa que o Estado não conseguiu alcançar. Causa da possível infelicidade antônimo de felicidade. (...) que as pessoas sejam felizes (provavelmente os professores, os alunos e a sociedade) ou as pessoas os empresários que num Estado Neo Liberal tem na liberdade de mercado e na lucratividade um significado de felicidade.

Por fim o discurso político ideológico da felicidade e do que é necessário para se dar bem na vida. Todos estes significados na coerência do pensamento desenvolvido até agora nos levam para o significado da meritocracia, somente encontrará a felicidade quem for capaz de se adaptar a estas mudanças e conseguir individualmente vencer os desafios. O mundo complexo, competitivo e exigente que necessitará de profissionais com grande repertório intelectual de conhecimento e de habilidade sócio emocionais, é um mundo cada vez mais privatizado e individualizado. Na necessidade de expansão do capital o horizonte promissor que se apresenta é o setor educacional assim a performatividade termo, que pego emprestada de Stephen Ball, das mudanças na reforma do Estado é perfeitamente descrita no desenvolvimento do discurso, não vai acontecer nos primeiros momentos mas a tendência nos próximos anos (...) e na palavra avanços que na AD Análise do Discurso) o significado de acordo com o dicionário apresenta léxicos como: "efeito de ir para frente, impulso de caminhar ou ato de progredir" e que na análise de discursos e mudanças social nos trás um significado potencial ambivalente: avanços na aprendizagem do estudante, o aluno terá mais elementos para aprender para se equipar, avanços tecnológico dos equipamentos existentes ou avanços do processo de terceirização através das parcerias público - privadas e portanto da gestão compartilhada. Portanto o significado potencial para a palavra "avanços" aqui é o de que como afirma Ball baseado nos estudos de Cerny.

O que estamos vendo no mundo, hoje (...) é(...) a reemergência do Estado como "mercantilizador" (....) Um novo capitalismo de Estado vai se impor. A fronteira entre o público e o privado, nesse contexto está sendo corroída, o que possibilita não apenas transformar o mercado mundial num palco do capital privado, como também e mais importante, fazer surgir uma ordem mundial invisível". (BALL apud CERNY.2004, P. 1108) 
Volume,13, n. 1: ano 2017

$\neg$ Os alunos serão muito beneficiados. Um indicativo de pacto social para dar um sentido de governo e viabilizar esse governo. Na sequência podemos perceber a ideologia partidária no instante em que o discurso político na sua subjetividade apresenta um projeto de qualidade total na construção de uma educação voltada para o trabalho e para produtividade baseada em um comportamento individual de felicidade e liberdade de mercado, fundamentado em uma ideologia neoliberal. Uma inspiração encontrada nos princípios do PSDB (Partido da Social Democracia Brasileira). Para consolidar esta informação é preciso destacar as assinaturas de Fernando Henrique Cardoso então Presidente da República e Luiz Carlos Bresser Pereira entre outros na lei $n^{\circ} 9.637$ de 15 de maio de 1998 que dispõe sobre a qualificação de entidades como organizações sociais $(\ldots)$

A secretária Raquel Teixeira está a mais de 10 anos na Gestão da Educação em Goiás. Todas as políticas públicas foram implementadas em sua gestão: Formação de professores (Parceladas), eleições para diretores, conselhos de pais, PPPE (Projeto Político Pedagógico da escola),PDE (Projeto de Desenvolvimento da Escola), PDDE(Projeto de Dinheiro Direto na Escola), Municipalização do ensino fundamental, ensino fundamental de 9 anos (Projeto seu enquanto Deputada Federal), Correção de fluxo na rede(programa de aceleração), e atualmente Projeto Novo Futuro(Escola de Tempo Integral) .Se tudo isto for olhado de longe sem nenhum estudo mais profundo para além das aparências poderíamos até dizer que este seria mesmo um discurso em defesa da escola pública de qualidade, porém basta uma breve análise crítico- social para percebermos que tudo isto possui uma lógica de qualidade neoliberal que conduz a educação para a privatização.

\section{Considerações Finais}

E finalmente podemos concluir que na subjetividade deste discurso está colocada a ideia do empreendedorismo educacional. Apresentando a educação como um grande negócio para um mercado sedento de mais opções de crescimento do capital, onde pais e alunos são consumidores em potencial. O Estado apresenta uma gestão racional para o sistema de ensino onde o seu papel seja apenas de gerenciamento, terceirizando sua responsabilidade direta com o financiamento e gestão das escolas. 
Volume,13, n. 1: ano 2017

O que está se configurando aqui são novos espaços de novas redes de políticas educacionais num cenário de neoliberalismo e de economicidade social através de parcerias diversas e impuras. Um hibridismo confuso que atuam contra o setor público. Como descreve Ball:

As privatizações referidas aqui são complexas, multifacetadas e interrelacionadas. Elas podem ser entendidas em relação ao desenvolvimento de um conjunto de relações complexas entre: (i) mudanças organizacionais nas instituições de setor público( recalibração e melhoria);(ii) novas formas de Estado e modalidades ( governança, redes e gestão de desempenho); (iii) privatização do próprio Estado; e (iv) os interesses do capital inquieto e os processos de mercantilização (serviços públicos como oportunidades de lucro e de fornecimento de prestação de serviços públicos efetivos.(BALL,2004 ,p.155).

Faz - se necessário uma reflexão mais aprofundada e minuciosa sobre cada significado para se obter a compreensão histórica, política e econômica das intenções do discurso para que se possa também analisar a conjuntura em que se insere, os interesses e as proposições de reformas e afirmações de poder embutidos em um jogo de palavras e afirmações que prometem um futuro incerto. É de fundamental importância, como afirma Foucault, examinar o que pode ser dito, por quem, e em que ocasiões. E ainda observa que "qualquer sistema de educação é uma forma política de manutenção ou modificação da apropriação de discursos e dos conhecimentos e poderes que eles carregam" (FAIRCLOUGH, 2001, p.123). Portanto, qualquer de educação pode ser entendido como manifestação política de poder.

Uma ênfase significativa em Foucault (1984) é sobre a luta de poder em torno de determinação das práticas discursivas: $\mathrm{O}$ discurso é não apenas o que traduz as lutas ou os sistemas de dominação, mas é a coisa para a qual e pela qual a luta existe, o discurso é o poder a ser tomado (FAIRCLOUGH, 2001 p.110)

Vale finalizar levantando algumas indagações. Quem ou quais serão os novos atores sociais que falarão a linguagem do público, do valor do privado e filantrópico? Para onde irá nos levar essa cultura do individualismo produzida pelo neoliberalismo? 
Volume,13, n. 1: ano 2017

\section{Referências Bibliográficas.}

BRESSER, PEREIRA Luiz Carlos. Democracia, estado e reforma gerencial. RAE : São Paulo. v. 50, n.1, jan./mar. 2010. P. 112-116. Disponível em: http://www.scielo.br/pdf/rae/v50n1/a09v50n1.pdf. Acesso em maio de 2016.

BRESSER, PEREIRA Luiz Carlos. A reforma do estado dos anos 90: lógica e mecanismos de controle. Lua Nova [online]. 1998, n.45, pp.49-98. ISSN 01026445. Disponível em: http://www.scielo.br/pdf/ln/n45/a04n45.pdf. Acesso em maio de 2016.

BALL, STEPHEN J. Performatividade, Privatização e o Pós Estado do Bem-Estar Social. Educ.soc. Campinas, vol.25 n.25, 2004. p.1105- 1126. Disponível em: http://www.scielo.br/pdf/es/v25n89/22613.pdf. Acesso em maio de 2016.

FAIRCLOUGH, NORMAN. Discurso e mudança social. Tradução. UNB: Brasília. 2001 https://pt.slideshare.net/praetece/discurso-e-mudana-social-norman-fairclough52484831. Acesso em maio de 2016.

ALTHUSSER, LOUIS. Aparelhos ideológicos de estado: Nota sobre os aparelhos ideológico de estado. 3 ed. Rio de Janeiro: Graal, 1985,P.09-10. 
Hypialins

REVISTA ELETRONICA REFLECIIONIS UFG / RE.

Volume,13, n. 1: ano 2017 